\section{Vacillating on vaccines}

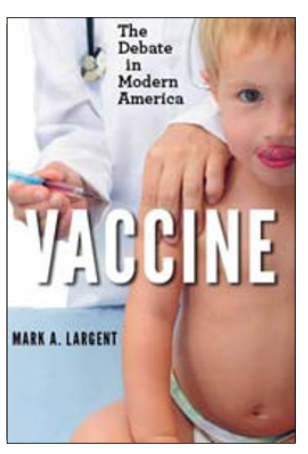

\section{Vaccine: The Debate in Modern America}

Mark A. Largent

Johns Hopkins University Press, 2012

232 pp., hardcover, \$34.95

ISBN: 1421406071

\section{Reviewed by Andrea Rusnock}

Why do so many Americans continue to believe that vaccines cause autism despite abundant scientific evidence to the contrary? Will even more research persuade the public? Mark Largent, a historian of science and medicine, thinks not. In his thought-provoking and carefully researched book, Largent argues that the passionate debate over autism and vaccines will continue as long as it serves as a proxy for more widespread anxieties about the barrage of shots young children receive.

Throughout the book, Largent makes it very clear that he supports vaccination's importance to individual and public health. Nonetheless, Largent criticizes public health officials' reluctance to address or even directly acknowledge American anxieties about childhood vaccinations.

Largent describes how the number of vaccinations has increased dramatically over the last half-century. Fifty years ago, American children received vaccinations against five life-threatening diseases-smallpox, polio, diphtheria, pertussis and tetanus. Today, they get over 30 shots for 14 infectious diseases in their first six years of life, with most administered before age 2. Largent argues that parents' suspicions about the safety and efficacy of vaccines, whether or not they are justified from a scientific or medical point of view, are directly related to this rise.

Public health officials tend to lump all vaccines into the same category of necessity: what Largent calls "the all-or-nothing approach." But, to parents, not all vaccines are equal: few refuse the polio vaccine, but many doubt the need for vaccination against chickenpox, a disease they may have had themselves as children. This is also because of the finding that a single vaccination does not provide the same immunity as the contracted illness. (Largent does not discuss the shift to the two-shot vaccination schedule developed in response to this finding, nor does he mention the decline in chickenpox since the advent of the vaccine.) In their calculations of risk, parents do not prioritize public health goals, and they are also suspicious of the profit motives of pharmaceutical companies that create and market new vaccines and of potential conflicts of interest among officials involved in vaccine policy who have ties to big pharma.

The roots of American anti-vaccination sentiment go back to the early twentieth century, when alternative health practitioners largely rejected vaccination in their struggle against orthodox physicians. They believed that compulsory vaccination was morally wrong and that vaccines were

Andrea Rusnock is at the University of Rhode Island, Kingston, Rhode Island, USA. e-mail: rusnock@mail.uri.edu ineffective and potentially harmful. During the 1990s, these views moved into the mainstream because of newly suggested links between the oral polio vaccine and the emergence of AIDS in Africa (which Largent makes clear have since been firmly rejected by the scientific community) and between the anthrax vaccine and Gulf War syndrome in veterans.

The most visible and lasting criticism of vaccination, however, has been the purported connection between autism and vaccines. Largent devotes three full chapters to this topic, and his account is the most careful and least polemical I have seen. Two strands of research-one in the United States on the use of the mercury-based preservative thimerosol in vaccines, the other put forth by Andrew Wakefield in Britain on the possible link between the MMR (measles, mumps and rubella) vaccine, gastrointestinal diseases and autism-became entwined in public debate ten years ago, and those links have since been proven to be false. Members of the medical community will no doubt take issue with Largent's evenhanded treatments of Wakefield and autism activist Jenny McCarthy, as well as with his condemnation of alarmist statements from a few outspoken vaccine advocates, such as the pediatrician Paul A. Offit, whose unwavering support of the all-or-nothing approach to vaccination has helped to polarize the debate, or the actress Amanda Peet, who called parents who chose not to vaccinate their children "parasites." (She has since apologized for using this term.) But such reactions underscore Largent's point: in spite of the hyperbole from vaccine advocates and the numerous scientific studies showing no link between MMR and autism, one-fifth of American parents still believe such a link exists.

Even more troubling to the medical community will be Largent's statistic that $40 \%$ of American parents have either delayed or refused vaccination for their children. Today, 17 states in the United States have adopted legislation that allows parents to refuse vaccination on philosophical grounds, a far broader category than the already existing medical and religious exemptions. Most of these parents are college educated, affluent, and comfortable challenging the authority of medical experts. And, because of the internet, they now have access to information from a variety of sources, both legitimate and illegitimate.

These parents are one of Largent's intended audiences, and his book provides an important overview of scientific research on the safety and side effects of vaccination. Largent also incorporates his own decisions about his daughter's vaccinations as an example of how one parent has navigated the competing claims about vaccines. Largent chose to vaccinate his daughter with all the recommended vaccines, but he spaced them so that she received only one vaccine at a time. Largent admits that there is no scientific evidence to support spacing vaccinations, although a recent study documented an increased risk of febrile seizure among infants who had received their pneumococcal and flu vaccines at the same time.

Largent points out that compulsory vaccination is not politically viable in a democratic society. Public health officials and primary care doctors must realize that parents need to be convinced-not forced-to vaccinate their children. And parents need to educate themselves and make wellinformed decisions about their children's vaccinations. Otherwise, the standoff will continue. 